\title{
Contribuições do Projeto "Circulação de Música de Câmara" para a Divulgação da Produção Cultural, Formação de Público e Transdisciplinaridade
}

Contributions of the Project "Chamber Music Tour" for the Dissemination of Cultural Production, Public Education and Transdisciplinarity

\section{Resumo}

Este artigo descreve ações do projeto de extensão Circulação de Música de Câmara, em desenvolvimento na Universidade do Estado de Minas Gerais (UEMG) durante o ano de 2018. O projeto consiste na realização de concertos de grupos de música de câmara formados por alunos da Escola de Música da UEMG nas unidades desta universidade em Belo Horizonte. Suas contribuições relacionam-se não só à formação dos alunos, mas também à potencialização da produção artística acadêmica. Além disso, o projeto estimula a interdisciplinaridade e a transdisciplinaridade, bem como a troca de experiências culturais entre a comunidade universitária. As contribuições do projeto estendem-se ao atual contexto da sociedade brasileira, carente de iniciativas voltadas para a ampliação de acesso a alguns bens culturais da humanidade.

Palavras-chave: Acesso à cultura; Formação de profissionais e cidadãos; Música de câmara

Alice Belém

José Antônio Baêta Zille

Fábio Ramos

alicebelem@yahoo.com.br

Universidade Estadual do Minas Gerais (UEMG) 
Abstract

This paper describes the actions of the project "Chamber Music Tour" under development at the Minas Gerais State University (UEMG) during the year 2018. The project consists in the production of concerts for students' chamber music ensembles in the units of such university in Belo Horizonte. Its contributions are related not only to the students' education, but also to the enhancement of academic artistic production. In addition, the project encourages interdisciplinarity and transdisciplinarity, as well as the exchange of cultural experiences among the university community. The project's contributions extend to the current context of Brazilian society, poor of initiatives that expand access to some of the cultural assets of mankind.

Keywords: Access to culture; Professional and citizen formation; Chambermusic 


\section{INTRODUÇÃO}

Na perspectiva antropológica, cultura é tudo aquilo produzido pela humanidade ao longo de sua existência. Inclui-se nesse universo toda sorte de bens materiais e imateriais que, para sua permanência, exige a difusão entre as gerações. Este é o caso da música, seja ela denominada popular ou erudita. Nesse contexto, o fazer artístico é uma atividade indispensável para a permanência e difusão dos bens culturais da humanidade, além de propiciar a fruição das obras. É, portanto, de relevância inquestionável. Nas palavras de Aranha (2006, p. 50):

O homem faz cultura por meio do seu trabalho, com o qual transforma a natureza e a si mesmo. E o aperfeiçoamento de suas atividades só é possivel mediante a educação, fator importantíssimo para a humanização e a socialização.

Mesmo que a relevância dos bens culturais seja inquestionável, a necessidade de iniciativas para a renovação do público e para melhor difusão da música erudita no Brasil é enorme, conforme destacada em publicações recentes como em Coelho (2002), Molistas (2014) e Mojola (2018). Segundo estes autores, fatores como redução de investimentos em orquestras e produções operísticas, ausência de uma programação de rádio e televisão de qualidade para divulgar a música erudita, carência de propostas voltadas para a formação de público, dificuldade de acesso à formação musical estão diretamente relacionados à problemática inicialmente mencionada.

Por outro lado, nas Universidades aumenta o número de alunos que concluem os cursos na área de Humanidades e Artes nos últimos anos, como indica o Censo do Ensino Superior, realizado pelo Ministério da Educação do Brasil (MEC) em 2016 (Tabela 1). ${ }^{1}$

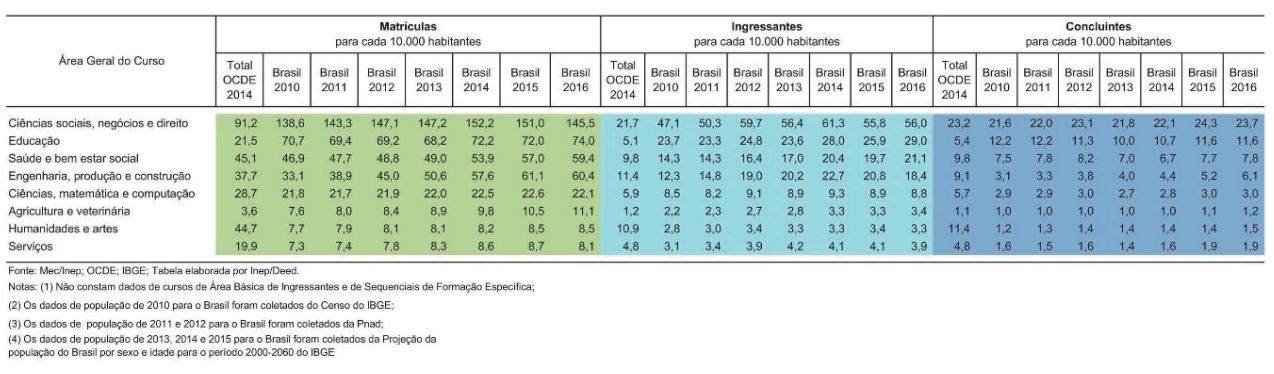

Nas Faculdades de Música, o aumento do número de graduados já fora comprovado em Freire, Miranda e Belém (2006). Segnini (2009) ratifica esse dado ao afirmar que nos primeiros cinco anos dos anos dois mil, de 894 matrículas em cursos superiores de música, passou-se para 5.200 matrículas, um aumento de aproximadamente $482 \%$.

Frente a essa situação, haveria de se esperar uma ampliação dos ambientes de atuação desses novos profissionais. Em contrassenso, o que se observa
Tabela 1: Censo da Educação Superior 2016 - Número de matrículas, ingressos e concluintes dos cursos de graduação para cada 10.000 habitantes, segundo a área geral do curso - Brasil 2010-2016 
é a redução de iniciativas governamentais no apoio a esse tipo de bem cultural, principalmente no que tange aos grandes grupos instrumentais. Nesse sentido, trabalhos de pequenos grupos instrumentais, denominados grupos de câmara², podem apresentar um caminho profissional mais viável, principalmente para o recém-egresso dos cursos de música.

A atividade camerística é frequentemente incluída nas programações culturais em todo o mundo, o que exige que o futuro profissional de música esteja preparado para esta demanda específica. Considere-se ainda que a música de câmara é parte importante da atuação do intérprete, por possibilitar um intenso desenvolvimento musical e aprimoramento da escuta, além de contar com um grande envolvimento da plateia durante os concertos.

Quando tocamos música de câmara, precisamos ter muito mais controle sob o que estamos fazendo. Há muitas trocas [entre os músicos] sobre a interpretação e acredito que o público aprecia isso. Quando o grupo inteiro está envolvido em fazer música, é como se os ouvintes estivessem assistindo mágica. (Neubauer, tradução nossa) ${ }^{3}$

Por se tratar de uma prática tão significativa e frente à maneira com que a música erudita tem sido considerada no Brasil, principalmente pelo poder público, reafirma-se que o trabalho camerístico pode apresentar-se como uma opção profissional na atualidade.

Outra possibilidade para ampliar o mercado do profissional na área de música e fomentar o acesso da população a esse tipo de bem cultural são iniciativas em que a música sai das salas de concertos e é levada às escolas, fundações culturais de outras áreas que não necessariamente a música (museus, por exemplo) ou a diversos outros lugares que não possuam o ambiente de uma sala de concerto, como por exemplo, em parques, praças, etc. Esses concertos geralmente são concebidos como didáticos, o que contribui imensamente com a formação de ouvintes.

O projeto de extensão Circulação de Música de Câmara4, em vigor na Univer-

2 Entende-se por música de câmara a obra composta para ser tocada em pequenos espaços, limitandose a poucos executantes. De acordo com BARON (1998), existem alguns ingredientes básicos que ajudam a definir música de câmara. O principal é o fato de que música de câmara é música em conjunto, ou seja, para dois ou mais artistas. Além disso, na música de câmara não há dois músicos tocando a mesma parte musical ao mesmo tempo e seu propósito geralmente não é apresentar a exibição virtuosística de apenas um membro do conjunto. Por último, a obra de câmara costuma propor uma situação de intimidade com o público. Diferente da orquestra tradicional, o grupo de músicos não precisa necessariamente de um regente, de forma que sua tradição remonta à música executada em ambientes nobres, quando esta servia de fundo para as refeições ou conversas. Existem diversos tipos de formações para esse gênero, incluindo-se duetos, trios, quartetos, quintetos e sextetos. No Brasil existe uma extensa produção para a música de câmara, que conta com obras de grandes compositores.

3 Disponível em:<https://www.youtube.com/watch?v=kTw2Z2ttkJE>.

$4 \quad$ O projeto apoiado pelo Programa Institucional de Apoio à Extensão da Universidade do Estado de Minas Gerais - UEMG através do Edital PAEX 2018/1 é coordenado pela Profa. Alice Belém em colaboração com o Prof. José Antônio Baeta Zille e tem como bolsista o aluno Fábio Ramos. 
sidade do Estado de Minas (UEMG) durante o ano de 2018, contempla os aspectos acima mencionados: o intuito de contribuir com a preparação do futuro profissional de música para a demanda da atuação camerística no mercado de trabalho e a realização de concertos em ambientes alternativos à sala de concerto.

Sob essa perspectiva, este projeto consiste na realização de concertos de grupos de música de câmara formados por alunos da Escola de Música da UEMG (ESMU/UEMG) nas unidades desta Universidade em Belo Horizonte - Escola de Design, Escola Guignard, Faculdade de Educação, Faculdade de Políticas Públicas Tancredo Neves e na própria Escola de Música. Ressalta-se que um dos eixos temáticos em destaque no projeto é a prática da música brasileira e que a execução de cada obra dos concertos é precedida por breves comentários, de modo a contribuir com a apreciação musical por parte do público.

Assim, esse projeto atua em diversas frentes. Uma delas é o notado viés extensionista, já que desloca o contexto do fazer artístico de dentro da escola, onde este germina, para além de seus muros, atingindo um público com pouca ou nenhuma familiaridade com música de câmara.

Nesse sentido, a proposta abrange a formação de público e busca exercer o papel de propagador de bens culturais da humanidade. Por sua vez, ao realizar suas atividades junto às unidades distintas de uma mesma universidade, o projeto busca minimizar os reflexos epistemológicos pelos quais o conhecimento se submeteu frente aos preceitos positivistas, fragmentando-o em várias áreas de saber. Se de um lado essa fragmentação proporcionou acúmulo de conhecimentos e desenvolvimento humano, possibilitando, entre outras coisas, uma verdadeira revolução tecnológica, por outro, criou verdadeiros nichos de saber capazes, até mesmo, de negar a importância e a pertinência dos demais nichos de saber, chegando a negar a legitimidade da interação e relação produtiva entre eles. Nesse sentido, o projeto acena com a possibilidade de instigar uma transdisciplinaridade entre as várias áreas do saber, até então, restritos a cada uma das unidades da universidade. Nessa perspectiva, o projeto vai ao encontro dos resultados das discussões que se iniciaram ainda nos anos 1970, no I Seminário Internacional Interdisciplinaridade - Problemas de Ensino e Pesquisa em Universidades, realizado na Universidade de Nice (França) e ratificado na Carta de Veneza de 1986, em que se defende a busca de uma abordagem transdisciplinar, na qual seja possível uma troca dinâmica entre as várias áreas do conhecimento. (Andalécio, 2009).

Além desses contextos, o projeto ainda atua num viés voltado ao ensino e à pesquisa. Nesse sentido, como já foi aventado, os alunos devem se apresentar em público, o que exige, além do preparo peculiar para uma performance, desenvolver as habilidades necessárias para a Música de Câmara. Além disso, devem se apoiar em pesquisas sobre autores e peças a serem interpretados, no sentido de fundamentar suas interpretações e apresentar ao público informações pertinentes. Este aspecto abrange as atividades do bolsista do projeto que também terá contato com todo o processo de produção de concertos dessa natureza. 


\section{METODOLOGIA}

O projeto conta com uma equipe composta por uma professora coordenadora; um professor colaborador; um aluno bolsista e alunos da disciplina Música de Câmara da Escola de Música da UEMG, que participam voluntariamente tocando nos concertos.

A professora coordenadora e o professor colaborador desenvolvem as funções de: realizar contatos com as diretorias das Unidades da UEMG em Belo Horizonte, informando sobre o projeto e discutindo estratégias para sua organização; avaliar as possibilidades de transporte; selecionar os alunos voluntários que atuarão como intérpretes; orientar o trabalho de apreciação musical que culminará nos concertos comentados; orientar o bolsista quanto à criação do site do projeto 5 , quanto à produção dos textos a serem incluídos nos programas de concerto, quanto à produção do material gráfico de divulgação, quanto à organização da logística e produção musical.

O aluno bolsista realiza o agendamento dos concertos em cada Unidade da UEMG e do transporte dos alunos voluntários; conduz toda a criação e alimentação do site do projeto; produz o material gráfico de divulgação, elabora textos a serem incluídos nos programas de concerto; planeja as necessidades logísticas do projeto; organiza o palco antes e depois do concerto; realiza o registro audiovisual das apresentações. Portanto, o bolsista é o produtor musical do projeto. Já os alunos voluntários irão tocar com grupos de câmara nos concertos.

A atuação do aluno bolsista, cujas atividades estão ligadas ao campo da produção musical, é de extrema relevância. Na vida profissional, nota-se a enorme necessidade de que os músicos estejam aptos a realizar a produção de sua própria atuação. Nota-se também que os músicos que se ocupam desta atividade são grandes conhecedores do métier e das especificardes da área, o que possibilita que os resultados do trabalho sejam otimizados. Dadas as diversas demandas de um curso de graduação em música, a área da produção musical acaba sendo colocada em segundo plano, o que resulta numa lacuna para o estudante de graduação brasileiro. É notório que esta lacuna precisava ser urgentemente preenchida. Desta maneira, justifica-se plenamente a atuação do aluno bolsista na área da produção musical. A etapa de produção musical está embasada na prática da coordenadora do projeto, bem como em publicações de renomados intérpretes sobre o tema (Cardassi, 2000).

No que diz respeito à atuação dos alunos voluntários no projeto, o desenvolvimento de seu trabalho camerístico baseia-se em metodologias relacionadas às práticas de música em conjunto, que incluem estudo individual do repertório por parte dos músicos, ensaios e audição de gravações de referência das obras seguindo os modelos estabelecidos pelas instituições musicais de maior renome em todo o mundo. Essa referência metodológica vem sendo aplicada pelo projeto, valorizando os aspectos prático-pedagógicos indissociáveis das ações previstas (ESMU/UEMG, 2018). 
A pesquisa de dados técnicos sobre a execução do repertório e questões estilísticas, especialmente no que diz respeito à música brasileira, sua relação com a historiografia musical e com a biografia dos compositores é também uma importante etapa metodológica do projeto (Cazarim; Ray, 2004). Deve-se destacar, como já mencionado, que essa pesquisa está também diretamente relacionada à produção dos textos a serem incluídos no programa, contendo informações relevantes sobre o repertório.

O projeto Circulação de Música de Câmara propõe ações relacionadas ao intercâmbio do conhecimento com a comunidade acadêmica e com interessados em geral, pautando-se, por isso, nos próprios pressupostos metodológicos da própria atividade extensionista universitária (UEMG, 2018).

Por fim, o projeto integra as referidas metodologias aos pressupostos discutidos na Conferência Mundial de Educação Superior, realizado em Paris, em 1998, nos quais a Universidade é chamada a promoção da interdisciplinaridade e ao diálogo com os setores produtivos e com a sociedade civil (Bernheim; Chauí, 2008).

\section{RESULTADOS}

Através da realização de dez concertos gratuitos durante o ano de 2018, precedidos por comentários sobre as obras, o projeto apresenta contribuições no sentido de ampliar público para música erudita. É importante lembrar que a apreciação musical que ocorre antes dos concertos também exerce impacto na formação cultural do público alvo.

Com relação à participação dos alunos voluntários, houve um número maior de participantes do que o inicialmente previsto. No projeto inicial, estava prevista a participação de 10 (dez) alunos voluntários e o projeto contou com 58 (cinquenta e oito) voluntários. Alguns desses músicos voluntários tocaram em mais de um concerto. Estes fatores demostram que os alunos perceberam a necessidade de ampliar os espaços para atuação de seus grupos de câmara, intuito primordial do projeto. Além disso, o acompanhamento dos concertos permitiu que a equipe do projeto verificasse melhora no desempenho dos músicos voluntários quando se tratavam de grupos que participaram de mais de um concerto. Isso comprova que o projeto vem colaborando para a melhoria da capacitação profissional dos alunos participantes.

Os concertos contaram com público amplo e diversificado, como mostram as fotos a seguir (Fig. 1 e Fig. 2). Esse aspecto é um demonstrativo que o projeto vem alcançando os propósitos de intercâmbio da produção cultural da Escola de Música da UEMG, ampliando o seu alcance. 
Figuras 1 e 2: Concerto do projeto Circulação de Música de Câmara. Fonte: arquivo dos autores.
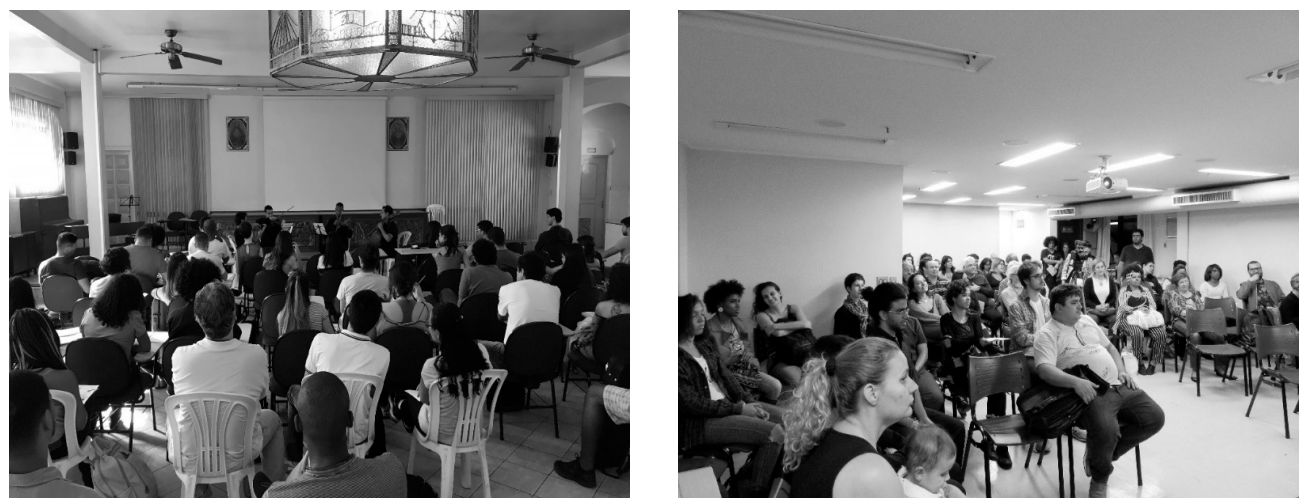

Por sua vez, viu-se o aumento do apoio da direção das Unidades à proposta, ao mesmo tempo em que lhes despertou o interesse em promover ações conjuntas com a Escola de Música. Posteriormente passou-se a discutir a integração do projeto com atividades já existentes nas unidades em sua segunda etapa. Esse interesse, juntamente com as primeiras propostas, acena com a concretização de um dos interesses do projeto, que é diminuir o distanciamento entres as áreas de conhecimentos na UEMG, representados por suas unidades.

Nota-se também o desenvolvimento das etapas relacionadas à produção musical. Nesse sentido, pôde-se observar que a pesquisa sobre o repertório e a preparação das atividades de apreciação musical resultaram no aumento da qualidade dos programas de concerto produzidos pelo bolsista.

\section{CONCLUSÕES}

O projeto de extensão Circulação de Música de Câmara vem se mostrando fundamental no sentido de divulgar a produção cultural da Escola de Música da UEMG junto à comunidade acadêmica e promover maior integração das unidades da universidade, ao mesmo tempo em que possibilita o contato do público leigo com esse tipo de produção.

Além disso, a avaliação das realizações do primeiro semestre de 2018 permitiu que o aluno bolsista, juntamente com os professores coordenadores, observasse pontos que poderiam ser ajustados para os concertos do segundo semestre de 2018, especialmente no que estava relacionado à logística do sistema de inscrição dos alunos voluntários e no agendamento dos concertos. Estes pontos já foram reformulados, de modo a ampliar ainda mais os impactos do projeto na comunidade acadêmica.

Numa análise mais abrangente, as contribuições do projeto se estendem ao atual contexto da cultura brasileira, carente de iniciativas voltadas para a ampliação de acesso à música de qualidade, já que o projeto apresenta impactos significativos na formação cultural do público. Espera-se que as iniciativas deste projeto sensibilizem a comunidade universitária, contribuindo para que em nossa sociedade este tipo de fazer cultural não se restrinja a poucos. 


\section{REFERENCIAS}

Andalécio, Aleixina Maria Lopes. A transdisciplinarifade na unviersidade: o discuro e a prática. RElIS - Revista Eletrônica de Comunicação, Informaçao e Inovação em Saúde. Rio de Janeiro, v. 3, p.84-90, st., 2009. Disponível em: <https://www.reciis.icict.fiocruz.br/index.php/reciis/article/view/795>. Acesso em: 16 jul. 2018.

Aranha, Maria Lúcia de Arruda. Filosofia da Educação. 2. ed. São Paulo: Moderna, 2006.

Baron, John Herschel. Intimate music: a history of the idea of chamber music. New York: Pendragon, 1998

Bernheim, Carlos Tünermann, Chauí, Marilena Souza. Desafios da universidade na sociedade do conhecimento. Brasília: Unesco, 2008.

Cardassi, Luciane. Pisando no Palco: prática de performance e produção de recitais. I Seminário Nacional de Pesquisa em Performance Musical. Belo Horizonte, 2000. Anais.... Escola de Música da UFMG, Belo Horizonte, 2000. CD-Rom.

Cazarim, Thiago e Ray, Sonia. Técnicas de Ensaio para a Performance Musical. In: IV Seminário de Pesquisa em Música da UFG (IV SEMPEM). Goiânia, 2004. Anais...: Mestrado em Música da UFG, Goiânica, 2004. CD-ROM.

Circulação de Música de Câmara. Site do Projeto. Disponível em: <https://cmusicadecamara.wixsite.com/uemg>. Acesso em: 16 jul. 2018.

Coelho, Lauro Machado. A música erudita do Brasil. Disponível em: <https://www.digestivocultural.com/ensaios/ ensaio.asp?codigo=7\&titulo=A_Musica_Erudita_no_Brasil>. Acesso em: 16 jul. 2018.

UEMG. Site da Universidade do Estado de Minas Gerais, 2018. Disponível em: <http://www.uemg.br/>. Acesso em: 04 mar. 2018

ESMU/UEMG Site da Escola de Música da Universidade do Estado de Minas Gerais, 2018. Disponível em: <http:// esmu.uemg.br/>. Acesso em: 04 mar. 2018.

Freire, Sérgio; Belém, Alice; Miranda, Rodrigo. Do conservatório à Escola: 80 anos de criação musical em Belo Horizonte. Belo Horizonte: Editora UFMG, 2006.

MEC. Ministério da Educação - Instituto Nacional de Estatística e Pesquisa. Censo da educação superior 2016

- Principais resultados. Disponível em: <http://download.inep.gov.br/educacao_superior/censo_superior/ documentos/2016/censo_superior_tabelas.pdf>. Acesso em: 16 jul. 2018.

Mojola, Celso. O futuro da música clássica: perspectivas para as próximas décadas. Revista Eletrônica Thesis, São Paulo, ano XIV, n. 28, p.60-71, $1^{\circ}$ semestre, 2018. ISSN 1806-762X

Molitsas, Denis Wagner. A música erudita no mercado fonográfico brasileiro atual: mitos e realidades. Revista d’Art, n.12. São Paulo. Disponível em: <http://sites.ffclrp.usp.br/viencontromusicologia/files/A\%20musica\%20 erudita\%20no\%20mercado\%20fonografico.pdf>. Acesso em: 15 jul. 2018.

Neubauer, Paul. What is chamber music? Disponivel em: <https://www.youtube.com/watch?v=kTw2Z2ttkJE>. Acesso em: 15 jul. 2018.

Segnini, Liliana R. Petrilli. Formação profissional e o trabalho dos músicos no Brasil: estatísticas oficiais e narrativas dos artistas selecionados pelo Programa Rumos Música. In: V Encontro de Estudos Multidisciplinares em Cultura (ENECULT). Salvador, BA, Brasil. 05/2009. Anais... Vol. 1, pp.1-3. 